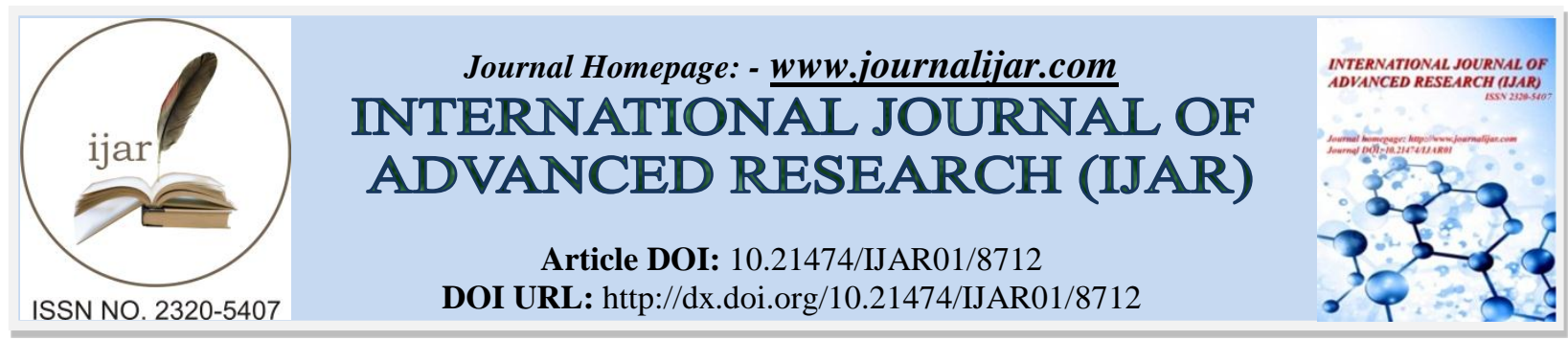

RESEARCH ARTICLE

\title{
STRESS HYPERGLYCAEMIA AND DEVELOP CARE PATHWAYS TO ATTAIN GLYCAEMIC CONTROL IN PERIOPERATIVE PERIOD IN PERSPECTIVE TO NURSING CARE: A REVIEW OF LITERATURE.
}

Anindita Mandal, Shiv Kumar Mudgal and Rakhi Gaur.

\section{Manuscript Info}

\section{Manuscript History}

Received: 16 January 2019

Final Accepted: 18 February 2019

Published: March 2019

Key words:-

Perioperative, Hyperglycaemia, Glycaemic control, Care pathways.

\begin{abstract}
Background: Surgical trauma stimulate the "stress response" which leads to release of counter-regulatory hormones which cause antiinsulin effect, hyperglycaemia, gluconeogenesis and decrease peripheral glucose uptake. Anaesthesia, especially general anaesthesia is more frequently associated with increased blood glucose level and higher levels of catecholamine, cortisol and glucagon. Risk of long perioperative hyperglycaemia cause impaired wound healing and wound infection and poor overall outcome of surgery.

Methodology: PubMed, Embess, Google Scholars and other electronic search engines were used to get high standard evidence regarding management of hyperglycaemia in perioperative period to get appropriate conclusions.

Results: The evidence of different sources indicates a great need to develop standard protocols to maintain the appropriate glycaemic level of patients with or without diabetes in perioperative period.

Conclusion: There is a rise in number of diabetic patients who come to operative room for different reasons. So it is a great challenge for perioperative nurse to maintain appropriate glycaemic level of patients during perioperative phase. The pathways should be developed to help a perioperative nurse to maintain the adequate glycaemic level of patient in this crucial period.
\end{abstract}

Copy Right, IJAR, 2019,. All rights reserved.

\section{Introduction:-}

Diabetes mellitus is a group of metabolic disorders delineate by elevated blood glucose level which is caused by problem in release of insulin, act of insulin or a combination of both. ${ }^{1}$ It can be categorised as 'type 1' (deficiency in insulin production), 'type 2' (insulin utilization) and Gestational Diabetes (glucose intolerance during pregnancy). ${ }^{2}$

Diabetes mellitus can be confirmed when a person's $\mathrm{HbAlc}$ is more than $6.5 \%$, plasma glucose $\geq 126 \mathrm{mg} / \mathrm{dL}$ (fasting at least 8 hours), plasma glucose $\geq 200 \mathrm{mg} / \mathrm{dL}$ (by oral glucose tolerance test) and plasma glucose $\geq$ $200 \mathrm{mg} / \mathrm{dL}$ (random) along with classical symptoms of hyperglycaemia. ${ }^{3}$

World Health Organization had reported about 108 million diabetic patients in 1980 and in 2014 the number of diabetes patients were 422 million. ${ }^{4}$ In 2017, International Diabetes Federation revealed, approximately 451 million adults were suffering from DM around the globe which will be rise up to 693 million by $2045 .{ }^{5}$ 
Perioperative hyperglycaemia was reported among 20 to 40 percent patients go through general surgery and around $80 \%$ after any cardiac surgery. $12-30 \%$ of patients experienced 'stress hyperglycaemia' during intra and/or postoperative period, didn't have a history of diabetes before surgery. ${ }^{6}$

Stress-induced hyperglycaemia is a normal response to surgical procedure, but related to many post-operative complications. ${ }^{7}$ Perioperative hyperglycaemia can be managed by administration of insulin but due to starvation and impaired dose of insulin/ hypoglycaemic agent, blood glucose can be drop down (hypoglycaemia) which is also linked to different postoperative complications and mortality.

So, proper glycaemic control during perioperative phase is vital to prevent complications, reduce length of hospital stay, reduction of overall cost and to achieve satisfactory and acceptable high standard results in surgery ${ }^{8,9}$ Proper glycaemic control can be achieved when perioperative personal (nurses and residents) would follow care pathways on glycaemic monitoring and administration of insulin, feeding schedule, concerns over hyperglycaemia or hypoglycaemia, and promulgate of evidence based protocols for glucose control. ${ }^{10}$

Purpose: The main aim of present literature review is to objectively analyse, assess and synthesize evidences on consequences of stress hyperglycaemia during perioperative phase and to draw care pathways to maintain appropriate glycaemic level of patients during perioperative period by utilizing most relevant previously conducted research studies.

Research Method: As it is a review of literature therefore, we used different key words to guide our search by using following electronic databases: PubMed, Embess, and Google Scholar. We included the studies which were published in English and from 2013 to December 2018.

\section{Effects of surgical stress and anaesthesia on glucose metabolism:}

Trauma associated with surgery is a causative factor of surgical stress and act as a potent activator of counter regulatory hormone (catecholamine, cortisol, glucagon \& growth hormone) and these hormones are responsible for secretion of inflammatory cytokines such as tumour necrosis factor- $\alpha$, interleukin- 6 and interleukin-1 $\beta .^{11}$ The volume of these hormones directly related to the types of surgeries (Laparoscopic surgeries show a diminished insulin resistance and hyperglycaemia when compared to open surgeries) ${ }^{12}$, location and duration of the surgery (thorax and abdominal surgeries are more accompanied with prominent and longer duration of hyperglycaemia than peripheral surgeries) ${ }^{13}$. Peak plasma concentration of ACTH, cortisol and catecholamine can be measured at the start of surgery as well as can persist in circulation up to 24 to 48 hours depending on severity of trauma. ${ }^{14}$

It is well documented that insulin sensitivity is negatively associated with cortisol and catecholamine release (it means increase level of cortisol and catecholamine decreases the insulin sensitivity). ${ }^{15}$ Post surgery, feedback mechanism of high circulating cortisol will be ineffective to inhibit further secretion of ACTH. So that concentration of hormone remains high in blood.

As, cortisol promotes gluconeogenesis through protein breakdown in liver, promotes lipolysis which increase production of glycerol and fatty acids (gluconeogenic precursors) from hydrolysis of triglyceride and inhibit glucose uptake in peripheral tissue by inactivation of GLUT4, glucose use by cell is inhibited and hyperglycaemia persist in blood. ${ }^{16}$

Catecholamine (Both epinephrine and norepinephrine) enhance glucagon secretion along with inhibit insulin release from cell in pancreas. ${ }^{14}$ Enhanced FFAs is also associated with impede glucose uptake ${ }^{17}$ as well as decreasing intracellular signalling cascade in skeletal muscle which is responsible for transporting glucose molecule. ${ }^{18}$ TNF- $\alpha$ interferes in synthesis along with translocation of glucose transporter GLUT-4 and reduce glucose uptake in peripheral tissues. ${ }^{19}$ All of these are noticeable specially on first postoperative day and may persist up to 9-21 days following surgery. ${ }^{6}$

There are a number of anaesthetic medications, each of which influences the glycaemic response during surgery. General anaesthetic agents cause hyperglycaemia and greater levels of catecholamine, cortisol, and glucagon than epidural/ local anaesthesia. ${ }^{20,21}$ As per review opiate given in higher doses at the time of postoperative recovery, block sympathetic nervous system and supress hypothalamic-pituitary axis which close down the hyperglycaemic 
response of surgery. ${ }^{22}$ A recent study on Etomidate vs. Thiopental has advocate that patients who received Etomidate have minor cortisol response by ACTH stimulus than control group of Thiopental. ${ }^{23}$

In case of regional anaesthesia, mechanism of neural blockade from T4 to S5 is the total prevention of the nociceptive signals from the surgical area to reach in central nervous system which prevents cortisol response. ${ }^{14}$ Epidural anaesthesia also inhibits release of catecholamine (irrespective of spinal segment), concentrations of noradrenaline and cortisol are not rise as such, prevents elevation of blood glucose levels. ${ }^{23}$ Volatile anaesthetic agents like halothane and isoflurane prevent normal production of insulin results a hyperglycaemic response ${ }^{24,25}$ and also increase hepatic glucose production. ${ }^{25}$

\section{Perioperative hyperglycaemia consequences:}

Surgical procedures and anaesthesia may results in changes of normal metabolism which can disturb normal glucose level resulting hyperglycaemia. That hyperglycaemia is associated with adverse perioperative outcomes as for example postoperative sepsis ${ }^{26}$, metabolic derangements, endothelial dysfunction ${ }^{27}$, cerebral ischemia ${ }^{28}$, poor wound healing ${ }^{29}$ and increased mortality ${ }^{30}$. Beside these, during perioperative phase the stress response may also lead other diabetic complications such as diabetic ketoacidosis ${ }^{31}$ or hyperglycaemic hyperosmolar syndrome ${ }^{32}$. Patients with diabetics need more hospitalizations, prolong stay, and more cost to manage than nondiabetics ${ }^{33}$. General complications of surgical wound are highly prevalent among diabetics and healing is really compromised when glycaemic levels are not well managed. ${ }^{34}$

Recognition of hypoglycaemia of a patient who has been undergone general anaesthesia or receiving sedative during perioperative phase is also necessary but difficult. If hypoglycaemia is unrecognized and unmanaged, it may cause neurological complications such as somnolence, unconsciousness, seizures, irreversible neurological insult ${ }^{35}$, increase morbidity/mortality in critically ill diabetic patients ${ }^{36}$ and longer duration of ICU/hospital stay ${ }^{37}$. Long starvation and high dose anti-diabetic during perioperative care can cause diminished blood glucose which is a potential of complication for hypoglycaemic shock.

Han and Kang reported, preoperative $\mathrm{HbAlc}>8 \%$ was a risk factor for wound complications among type 2 diabetic patients experiencing total knee arthroplasty. ${ }^{38}$ In the same way, Dronge et al. conveyed, among 490 diabetic patients who had major non-cardiac surgery, $\mathrm{HbAlc}>7 \%$ was highly associated to increased infectious complications compared to patients having HbA1c $<7 \% .{ }^{39}$ So, HbAlc should be strictly below $9 \%$ or if possible below $8 \%$. If result is greater than $9 \%$, nurse should contact physician. (Rönnemaa 2015). ${ }^{40}$

\section{Attainment of Glycaemic targets during perioperative care for patients with diabetes:}

Studies among general surgery, cardiac and other ICU patients had revealed a clear association of inpatient hyperglycaemia $(>180 \mathrm{mg} / \mathrm{dl})$ with adverse outcomes such as surgical site infections, delayed wound healing along with increased duration of hospital stay. ${ }^{41}$ So various organizations had worked on it and fixed a target blood glucose level to achieve satisfactory outcome which are $(140-180) \mathrm{mg} / \mathrm{dl}$ in critically ill patients, $(140-200) \mathrm{mg} / \mathrm{dl}$ for general patients with or without diabetes and $<180 \mathrm{mg} / \mathrm{dl}$ during intraoperative phase recommended by American Association of Clinical Endocrinologists Task Force, American College of Physicians (ACP) and The Society for Ambulatory Anaesthesia (SAMBA) respectively. ${ }^{6}$

To reach glycaemic target, perioperative personal has to be expertise on basic fundamentals of glycaemic control ${ }^{42}$ such as - 


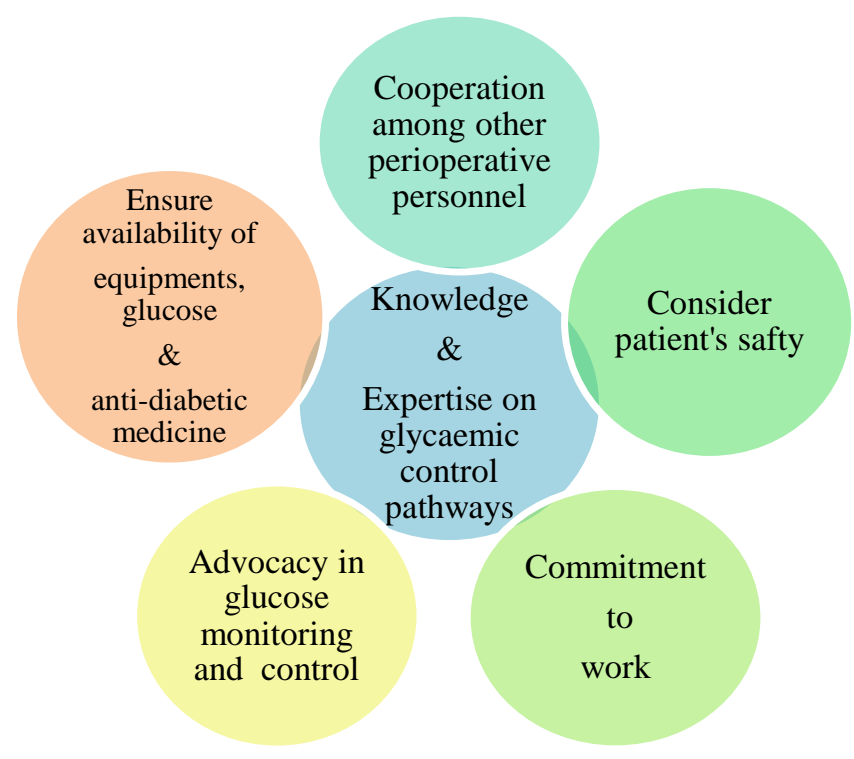

Maintenance of basic fundamentals can help to achieve goals of glycaemic control during perioperative phase. Those are:

- To reduce overall patient morbidity and mortality.

- To avoid severe hyperglycaemia or hypoglycaemia.

- To maintain acid/base, electrolyte and fluid balance.

- To prevent of ketoacidosis and hyperglycaemic hyperosmolar syndrome.

- To maintain glycaemic target levels ${ }^{43,44,45}$

Why it is needed to develop a care pathway to attain glycaemic control during perioperative care:

Rubin DJ et al. ${ }^{46}$ found lack of diabetes knowledge and preparedness to manage diabetes among nurses as well as residents in surgery, family practice and internal medicine and this study had recommended for additional education to provide optimal care to diabetic patients. Nurses had made procedural errors and wrong route along with charting errors by Mohammed MA et al. ${ }^{47}$ Therefore, when a patient with a known or suspected case of diabetes, it is good to follow certain paths by patients and physician (Scobie 2014) ${ }^{48}$ Lemmens 2008 developed care pathways to meet patient's expectation and needs and utilized multidisciplinary approach during the perioperative phase. ${ }^{49}$

A care pathway could be evolved and advanced with the support of recent guidelines regarding, effective communication with patient, family and team members, roles \& responsibilities of each member of multidisciplinary team with sequence of activities. The main aim is to enhance the quality of care, decrease risk, and enhance satisfaction of patient and utilization of available resources effectively to reduce hospitalization cost. (Macario et al. 1998, De Bleser et al.2006 ${ }^{50,51}$ Yu CHY et al had also proposed that Insulin order set improves glycaemic control and process of care and it also improved nurse's satisfaction, found in university of Toronto, Ontario, Canada. ${ }^{52}$

Typically, each phase of perioperative care (preoperative, intraoperative and postoperative) contains several activities that nurses can perform to control glycaemia as per Collaborative Care Guidelines for Perioperative Nurses. 2013. ${ }^{53}$ Since, there was a shortage of generally accepted guidelines for maintaining adequate glycaemic level during perioperative phase (Shah et al. 2014) ${ }^{54}$ It is also reported by some anecdotal reports that there is lack of care planning, inadequate knowledge along with experience among nurses in clinical field and failure of communication between team. ${ }^{55}$ So, reviewer try to develop the pathways to manage glycaemia during perioperative care among adults with DM in perspective of nursing.

Preoperative Nursing path to control glycaemic status: Pre-operative phase starts at the time of making decision of surgery and ends when patient is brought into the OR. Preliminary blood glucose monitoring is compulsory for all, irrespective existing diseases. 


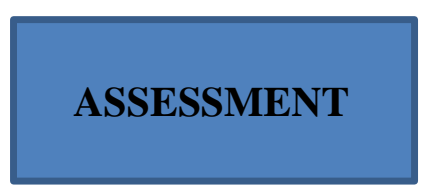

GOAL

INTERVENTIONS
Obtain history about onset, duration, symptoms of diabetes, anti- diabetic medication, complementary therapy and their compliance ${ }^{42}$

\section{Identify the contributing factors of hyper or hypoglycaemia}

- Type of surgery

- Choice of anaesthesia ${ }^{56}$

- Assess HbA1C (If not performed in the prior 3 months)

- $\quad$ RBS should be measured 4 hourly for DM patients on insulin and 8 hourly for patients on oral hypoglycaemic agents

- Obtain current blood glucose level 1 hour before starting surgery ${ }^{57}$

- Target glucose range $80-180 \mathrm{mg} / \mathrm{dl}$

- Acceptable $<200 \mathrm{mg} / \mathrm{dl}$

1. All diabetic medications should be continued until the night before surgery as a routine.

2. On the day of operation there will be no breakfast and diabetics should be placed first on OT list $^{57}$

3. For Type 1 diabetics, if they routinely use long acting insulin, $60-80 \%$ doses can be given, no need to hold ${ }^{58}$

4. Type 2 diabetic managed by diet alone, doesn't need any therapy peri-operatively. Supplemental short (regular) or rapid acting (lispro, aspart) insulin can be provided as correction for those who has risen glucose level over desired target ${ }^{58}$

\section{Type 2 diabetics treated with $\mathrm{OHA}$ should hold their morning dose $\mathrm{e}^{57}$}

In case of minor surgery metformin can be continued on the day of surgical procedure (one missed meal) as per JBDS guidelines. In case of major surgery metformin can be stopped before $48 \mathrm{hrs}$ as there is risk of lactic acidosis. ${ }^{59}$

\section{Special considerations in preoperative care:}

1. Prolong fasting should be avoided. Low carbohydrate diet facilitates insulin dose and enhanced glucose control. ${ }^{60}$

2. If patient has episodes of nocturnal hypoglycaemia then night insulin dose should be reduced.

3. If blood glucose level is more than $400 \mathrm{mg} / \mathrm{dl}$, symptoms of DKA or HSS, postponed the elective surgery and consult the diabetes specialist.

4. Concern related to Chlorpropamide induced hypoglycaemia can be stopped 3 days prior and substitute with other medicine as prescribed by physician. ${ }^{57}$

5. Even when a patient has a chance of getting hypo, long acting insulin (glargine) can be substituted with short/intermediate-acting insulin (2-3) days prior to surgery. Glucose level can be steadied by mixture of intermediate insulin (NPH) with rapid /short acting insulin BD or regular insulin before meals and intermediate acting insulin at bedtime. ${ }^{57}$ Otherwise use basal bolus therapy rather than mixed therapy. 
Intraoperative Nursing path to control glycaemic status of diabetic: The intraoperative phase initiates when patient on operating table and finishes when he/ she is shifted to post-anaesthesia zone.

ASSESSMENT

GOAL
- Monitor blood glucose level hourly ${ }^{57}$

- Understand type, duration and severity of surgery and hyperglycaemia

\section{Consider individual target glucose levels}

- $\quad 140-180 \mathrm{mg} / \mathrm{dl}$ among critically ill patients

- $140-200 \mathrm{mg} / \mathrm{dl}$ for all with or without diabetes

\section{INTERVENTIONS}

1. In case of minor surgery (less than two hours), Type 1 or insulin-treated type 2 diabetics who use SC insulin (short or rapid-acting insulin) will take their usual morning dose after the surgery and before eating. ${ }^{58}$

2. If patient can have expected to eat and drink within 4 hours of surgery, no need of regimen. ${ }^{57}$

3. In case of major surgery, follow $5 \%$ glucose + insulin regimen during OT. [Any of three intraoperative regimens can be used; Albert Thomas, CMC, WATTS] ${ }^{57}$

Intra-operative insulin administration

CMC regimen $^{57}$

\begin{tabular}{|c|c|}
\hline Blood glucose $\mathrm{mg} / \mathrm{dl}$ & Insulin infusion rate \\
\hline$<75$ & No insulin; $100 \mathrm{ml} 5 \%$ glucose over 15 minutes \\
\hline $75-100$ & No insulin; $100 \mathrm{ml} 5 \%$ glucose over 1 hour \\
\hline $100-150$ & 1 unit Actrapid in100 $\mathrm{ml} 5 \%$ glucose over 1 hour \\
\hline $150-200$ & 2 unit Actrapid in $100 \mathrm{ml} 5 \%$ glucose over 1 hour \\
\hline $200-250$ & 3 unit Actrapid in $100 \mathrm{ml} 5 \%$ glucose over 1 hour \\
\hline $250-300$ & 4 unit Actrapid in $100 \mathrm{ml} 5 \%$ glucose over 1 hour \\
\hline$>300$ & 4 unit Actrapid in $100 \mathrm{ml} \mathrm{0.9 \%} \mathrm{\%} \mathrm{Normal} \mathrm{Saline} \mathrm{over} 1$ hour \\
\hline
\end{tabular}

Postoperative Nursing path to control glycaemic status: This phase literally begins at post anaesthesia care and ends with follow-up evaluation at clinical area or at discharge.

\section{ASSESSMENT}

\section{GOAL}

- Monitor blood glucose level 1-2 hourly till first feed then 4 hourly ${ }^{57}$

- Early identification of hypo and hyperglycaemia symptoms

Consider target glucose within 80 - $180 \mathrm{mg} / \mathrm{dL}$ (By American Diabetes Association) 


\section{INTERVENTIONS}

\section{Special consideration:}

Manage complication like DKA by providing IV fluids for dehydration, bicarbonate for acidosis, insulin for hyperglycaemia, $\mathrm{K}+$ for electrolytes imbalance and antibiotics to control infection. ${ }^{57,61}$

\section{Conclusion:-}

It was concluded by the review that the number of patients of diabetes is dramatically increasing and as a result, the number of patient with DM undergoing surgical procedures is also increasing with the same pace. Moreover, the risk for stress hyperglycaemia during perioperative period exists in all patients. Therefore, it is deemed necessary to provide quality care and follow the glycaemic control pathways to reach and maintain glycaemic target during perioperative phase to achieve high standard results of surgical procedure.

\section{References:-}

1. American Diabetes Association. Diagnosis and classification of diabetes mellitus. Diabetes Care. 2010;33(supplement 1): 62-9. doi: 10.2337/dc10-S062. [PMC free article] [PubMed] [Cross Ref]

2. Raju TA, Torjman MC, Goldberg ME. Perioperative Blood Glucose Monitoring in the General Surgical Population. J Diabetes Sci Technol. 2009; 3(6): 1282-87. doi: 10.1177/193229680900300607

3. American Diabetes Association. Standards of medical care in diabetes-2014. Diabetes Care. 2014;37(supplement 1): 14-80. doi: 10.2337/dc14-s014. [PubMed] [Cross Ref]

4. World Health Organization. Diabetes Key Facts. Published on 30 October 2018

5. Cho NH, Shaw SE, Karuranga S, Huang Y, Da Rocha Fernandes JD, Ohlrogge AW, Malanda B. IDF Diabetes Atlas: Global estimates of diabetes prevalence for 2017 and projections for 2045. Diabetes research and clinical practice.2018; $138: 271-81$

6. Duggan EW, Carlson K, Umpierrez GE. Perioperative Hyperglycaemia Management: An Update. Anaesthesiology. 2017; 126(3): 547-60. doi:10.1097/ALN.0000000000001515

7. Barker P, Creasey PE, Dhatariya K et al. Peri-operative management of the surgical patient with diabetes 2015. Association of Anaesthetists of Great Britain and Ireland Anaesthesia 2015; 70:1427-1440

8. Stolar MW, Hoogwerf BJ, Gorshow SM, Boyle PJ, Wales DO. Managing type 2 diabetes: going beyond glycaemic control. Journal of Managed Care Pharmacy. 2008;14(5): 2-19. [PubMed] 
9. Mesotten D, Van Den Berghe G. Clinical potential of insulin therapy in critically ill patients. Drugs. 2003; 63(7):625-36. doi: 10.2165/00003495-200363070-00001. [PubMed] [Cross Ref]

10. Sebranek JJ, Lugli AK, Coursin DB. Glycaemic control in the perioperative period. British Journal of Anaesthesia. 2013; 111 (suppl 1) :18-34. Available on: https://doi.org/10.1093/bja/aet381

11. Esposito K, Nappo F, Marfella R, Giugliano G, Giugliano F, Ciotola M, Quagliaro L, Ceriello A, Giugliano D. Inflammatory cytokine concentrations are acutely increased by hyperglycaemia in humans: Role of oxidative stress. Circulation. 2002; 106:2067-72. [PubMed]

12. Thorell A, Efendic S, Gutniak M, Häggmark T, Ljungqvist O. Insulin resistance after abdominal surgery. Br J Surg. 1994; 81:59-63. [PubMed]

13. Clarke RS. The hyperglycaemic response to different types of surgery and anaesthesia. Br J Anaesth. 1970; 42:45-53. [PubMed]

14. Singh M. Stress response and anaesthesia altering the pre and post-operative management. Indian J. Anaesth. 2003; 47 (6): 427-34

15. Werb MR, Zinman B, Teasdale SJ, Goldman BS, Scully HE, Marliss EB. Hormonal and metabolic responses during coronary artery bypass surgery: role of infused glucose. The Journal of Clinical Endocrinology \& Metabolism. 1989;69(5):1010-18. doi: 10.1210/jcem-69-5-1010. [PubMed] [Cross Ref]

16. Burton D, Nicholson G, Hall G. Endocrine and metabolic response to surgery. Continuing Education in Anaesthesia, Critical Care \& Pain. 2004;4: 5

17. Roden M, Price TB, Perseghin G, Petersen KF, Rothman DL, Cline GW, Shulman GI. Mechanism of free fatty acid-induced insulin resistance in humans. J Clin Invest. 1996;97: 2859-65. [PubMed]

18. Dresner A, Laurent D, Marcucci M, Griffin ME, Dufour S, Cline GW, Slezak LA, Andersen DK, Hundal RS, Rothman DL, Petersen KF, Shulman GI. Effects of free fatty acids on glucose transport and IRS-1-associated phosphatidylinositol 3-kinase activity. J Clin Invest. 1999; 103:253-9. [PubMed]

19. Hotamisligil GS, Murray DL, Choy LN, Spiegelman BM. Tumour necrosis factor alpha inhibits signalling from the insulin receptor. Proc Natl Acad Sci USA. 1994; 91:4854-8. [PubMed]

20. Rehman H. U., Mohammed K. Perioperative management of diabetic patients. Current Surgery. 2003;60(6):607-11. doi: 10.1016/j.cursur.2003.07.002. [PubMed] [Cross Ref]

21. Reddy GVK, Rao MMM, Obulesu G, Mahaboob RS. The study of blood glucose level changes during general anaesthesia in patients undergoing surgery. IAIM, 2017; 4(1): 110-15.

22. Desborough JP. The stress response to trauma and surgery. British Journal of Anaesthesia. 2000; 85(1): 109 -17. Available on: https://doi.org/10.1093/bja/85.1.109

23. Absolom A, Pledger D, Kong A. Adrenocortical function in critically ill patients $24 \mathrm{~h}$ after a single dose of etomidate. Anaesthesia. 1999; 54: 861-7

24. Desborough JP, Jones PM, Persaud SJ, Landon MJ, Howell SL. Isoflurane inhibits insulin secretion from isolated rat pancreatic islets of Langerhans. British Journal of Anaesthesia. 1993;71(6):873-76. doi: 10.1093/bja/71.6.873. [PubMed] [Cross Ref]

25. Lattermann R., Schricker T, Wachter U, Georgieff M, Goertz A. Understanding the mechanisms by which isoflurane modifies the hyperglycaemic response to surgery. Anaesthesia and Analgesia. 2001;93(1):121127. [PubMed]

26. Rayfield EJ, Ault MJ, Keusch GT, Brothers MJ, Nechemias C, Smith H. Infection and diabetes: the case for glucose control. The American Journal of Medicine. 1982;72(3):439-50. doi: 10.1016/0002-9343(82)905113. [PubMed] [Cross Ref]

27. Hempel A, Maasch C, Heintze U. High glucose concentrations increase endothelial cell permeability via activation of protein kinase Ca. Circulation Research. 1997;81(3):363-71. doi: 10.1161/01.res.81.3.363. [PubMed] [Cross Ref]

28. Pulsinelli WA, Levy DE, Sigsbee B, Scherer P, Plum F. Increased damage after ischemic stroke in patients with hyperglycaemia with or without established diabetes mellitus. The American Journal of Medicine. 1983;74(4):540-44. doi: 10.1016/0002-9343(83)91007-0. [PubMed] [Cross Ref]

29. Aminian A, Kashyap SR, Burguera B. Incidence and clinical features of diabetic ketoacidosis after bariatric and metabolic surgery. Diabetes Care. 2016; 39:50-3. [PubMed]

30. Jones KW, Cain AS, Mitchell JH, et al. Hyperglycaemia predicts mortality after CABG: postoperative hyperglycaemia predicts dramatic increases in mortality after coronary artery bypass graft surgery. J Diabetes Complications. 2008;22: 365-70. [PubMed]

31. Walker M., Marshall SM, Alberti KGMM. Clinical aspects of diabetic ketoacidosis. Diabetes/Metabolism Reviews. 1989; 5(8): 651-63. doi: 10.1002/dmr.5610050803. [PubMed] [Cross Ref] 
32. Brenner WI, Lansky Z, Engelman RM, Stahl WM. Hyperosmolar coma in surgical patients: an iatrogenic disease of increasing incidence. Annals of Surgery. 1973; 178(5): 651-54. doi: 10.1097/00000658-19731100000017. [PMC free article] [PubMed] [Cross Ref]

33. American Diabetes Association. Economic costs of diabetes in the U.S. in 2012. Diabetes Care. 2013; 36(4) :1033-46. doi: 10.2337/dc12-2625. [PMC free article] [PubMed] [Cross Ref]

34. Zacharias A, Habib RH. Factors predisposing to median sternotomy complications: deep vs superficial infection. Chest. 1996; 110(5): 1173-78. doi: 10.1378/chest.110.5.1173. [PubMed] [Cross Ref]

35. Angelini G, Ketzler JT, Coursin DB. Perioperative care of the diabetic patient. ASA Refresher Courses in Anaesthesiology. 2001;29(1):1-9. doi: 10.1097/00126869-200129010-00002. [Cross Ref]

36. Finfer S., Bellomi R., Blair D., et al. Intensive versus conventional glucose control in critically Ill patients. The New England Journal of Medicine. 2009;360(13):1283-97. doi: 10.1056/nejmoa0810625. [PubMed] [Cross Ref]

37. Turchin A, Matheny ME, Shubina M, Scanlon SV, Greenwood B, Pendergrass ML. Hypoglycemia and clinical outcomes in patients with diabetes hospitalized in the general ward. Diabetes Care. 2009; 32 (7): 1153-5 doi: 10.2337/dc08-2127. [PMC free article] [PubMed] [Cross Ref]

38. Han HS, Kang SB. Relations between long-term glycaemic control and postoperative wound and infectious complications after total knee arthroplasty in type 2 diabetics. Clin Orthop Surg. 2013; 5:118-23.[PubMed]

39. Dronge AS, Perkal MF, Kancir S, Concato J, Aslan M, Rosenthal RA. Long-term glycaemic control and postoperative infectious complications. Arch Surg. 2006; 141:375-80.

40. Rönnemaa T. Leikkaukset ja Diabetes. Terveysportti. 2015. Available on: http://www.terveysportti.fi/dtk/shk/koti?p_haku=diabetes\%20leikkaus.

41. Kwon S, Thompson R, Dellinger P, Yanez D, Farrohki E, Flum D. Importance of perioperative glycaemic control in general surgery: A report from the Surgical Care and Outcomes Assessment Program. Ann Surg. 2013; 257:8-14. [PubMed]

42. Vorobiova A, Päivärinta A. Proper Glycaemic Control of Adult Diabetic Patient in Perioperative Nursing Care: A Literature Review. Centria University of Applied Sciences. 2015

43. Rehman HU, Mohammed K. Perioperative management of diabetic patients. Current Surgery. 2003;60(6):60711. doi: 10.1016/j.cursur.2003.07.002. [PubMed] [Cross Ref]

44. Meneghini LF. Perioperative management of diabetes: translating evidence into practice. Cleveland Clinic Journal of Medicine. 2009;76(4): 53-59. doi: 10.3949/ccjm.76. s4.09. [PubMed] [Cross Ref]

45. Moghissi ES, Korytkowski MT, DiNardo M. American Association of Clinical Endocrinologists and American Diabetes Association consensus statement on inpatient glycaemic control. Diabetes Care. 2009;32(6):1119-31. doi: 10.2337/dc09-9029. [PubMed] [Cross Ref]

46. Rubin DJ, Moshang J, Jabbour SA. Diabetes knowledge: are resident physicians and nurses adequately prepared to manage diabetes? Endocr Pract. 2007;13(No. 1)

47. Mohammed MA, Zein El -Deen Hafez M. Nurses knowledge, skill and attitudes toward insulin errors for Diabetic critical ill patients. AAMJ. 2013; 11(4).

48. Scobie A. Fast Facts: Diabetes Mellitus. 5th edition. Abingdon: Oxford GBR. Health Press Limited; 2014.

49. Lemmens L, Zelm RV, Vanhaecht K, Kerkkamp H. Systematic review: indicators to evaluate effectiveness of clinical pathways for gastrointestinal surgery. Journal of evaluation in clinical practice. 2008; 14(5): 880-87. Available on: https://doi.org/10.1111/j.1365-2753.2008.01079.x

50. Bleser LD, Waele KD, Vanhaecht K, Vlayen J, Sermeus W. Defining pathways. Journal of nursing management. 2006; 14(7): 553-63. https://doi.org/10.1111/j.1365-2934.2006.00702.x

51. Macario A, Horne M, Goodman S, Vitez T, Dexter F, Heinen R et al. The effect of a perioperative clinical pathway for knee replacement surgery on hospital costs. Anesth Analg. 1998;86(5):978-84.

52. Yu CHY. Sun XH. Nisenbaum R. Halapy H. Insulin order set improves glycaemic control and process of care. The American Journal of Medicine. 2012; 125:922-28

53. Collaborative Care Guidelines for Perioperative Nurses. Model of Care Initiative in Nova Scotia. Version 18; 2013.

54. Shah M, Apsey H, Stearns J, Schlinkert R, Seifert K, Cook C. Guidelines to Improve Perioperative Management of Diabetes Mellitus: An Example of a Successful Quality Initiative. Diabetes Management. 2014; 4(4): 327-37.

55. Joint British Diabetes Societies (JBDS) for Inpatient Care Group ...Available on:

56. https://abcd.care/joint-british-diabetes-societies-jbds-inpatient-care-group

57. Sudhakaran S, Surani SR. Guidelines for Perioperative Management of the Diabetic Patient. Surgery Research and Practice. 2015; Article ID 284063. Available on: http://dx.doi.org/10.1155/2015/284063 
58. Thomas N, Kapoor N, Velavan J, Vasan SK. A Practical Guide to Diabetes Mellitus. 7th edition. New Delhi: Jaypee brothers; 2016.p. 445-60

Khan NA, Ghali WA, Cagliero E. Perioperative management of blood glucose in adults with diabetes mellitus. Available on: https://www.uptodate.com/.../perioperative-management-of-blood-glucose-in-adults-w...

60. Bailey CJ, Turner RC. "Metformin”. The New England Journal of Medicine. 1996; 334(9): 574-579.

61. Gosmanov AR, Umpierrez GE. Management of hyperglycaemia during enteral and parenteral nutrition therapy. Curr Diab Rep. 2013; 13:155-62. [PubMed]

62. Developing Registered Nurse Competency in Diabetes Care. Elizabeth Ortiz University of Nevada. Las Vegas; 2016. Available on: https://digitalscholarship.unlv.edu/thesesdissertations/2716 